\title{
Current engineering and clinical aspects of needle-free injectors: A review ${ }^{\dagger}$

\author{
Abdul Mohizin ${ }^{1}$ and Jung Kyung Kim²,* \\ ${ }^{1}$ Department of Mechanical Engineering, Graduate School, Kookmin University, Seoul 02707, Korea \\ ${ }^{2}$ School of Mechanical Engineering and Department of Integrative Biomedical Science and Engineering, Graduate School, \\ Kookmin University, Seoul 02707, Korea
}

(Manuscript Received June 14, 2018; Revised September 17, 2018; Accepted October 9, 2018)

\begin{abstract}
Needle-free injectors can be used to achieve non-invasive drug delivery by impregnating biological barriers. They are considered as the future of drug delivery and therapeutic applications. The history of needle-free injectors dates back to the 1940s and these devices have been constantly evolving since then. Their operating principles and applications have been improved over the years. Herein, we review the current engineering mechanisms and clinical aspects of needle-free microjet injectors. The present study focuses on using engineering approaches to deal with various factors that affect the penetration and dispersion characteristics of the microjet.
\end{abstract}

Keywords: Fluid dispersion; Microjet; Needle-free injection; Penetration; Skin; Transdermal drug delivery

\section{Introduction}

Needle-free jet injectors (NFJIs) are devices with noninvasive drug delivery capabilities, and they are the result of the quest for pain-free needle-free drug administration. These devices use a high-velocity jet to puncture the skin surface and deliver drugs to the required depth without using a needle. Conventionally, NFJIs have been most commonly used for vaccinations and insulin delivery applications [1-4], but recent advancements in science and technology have widened the scope of the application of these systems. Herein, we provide an overview of the historical development and current trends of needle-free injection technology. The study focuses on the mechanistic and engineering characteristics of the system.

\section{Background and history}

Even though the concept of these systems originated in the 1860s when a technique called aquapuncture was reported in France [1], the modern history started with a patent in 1936 [5], and in the 1940s, hypospray, an insulin self-injection device, was introduced $[1,4,6]$. NFJIs were being developed for delivering vaccines and medicines. Earlier forms of injectors were of multi-use type that could deliver a vaccine through the same nozzle and fluid stream to multiple patients; these injectors can be referred to as multi-use nozzle jet injectors (MUN-

\footnotetext{
${ }^{*}$ Corresponding author. Tel.: +82 2910 4767, Fax.: +82 29104839

E-mail address: jkkim@kookmin.ac.kr

${ }^{\dagger}$ Recommended by Associate Editor Simon Song

(C) KSME \& Springer 2018
}

JIs) [3, 7]. They were widely used until the 1980s in mass immunization campaigns worldwide $[3,7,8]$. These devices could be used to vaccinate up to 1000 patients per hour and deliver vaccines from multi-dose vials (up to 50 doses per vial). However, a hepatitis B outbreak in 1985 was linked to the use of MUNJIs and presumed to have occurred owing to the contamination of the injector by body fluids [9]. On further investigation, it was found that in a few samples, injectors were contaminated with small amounts of blood. Because of this incident, various health authorities, including World Health Organization (WHO), discontinued the use of MUNJIs $[7,8]$. The abilities of these high-workload devices in terms of administering safe mass immunizations were unprecedented, and further modifications were made to reduce the risk of blood-borne infections. The addition of a disposable cap is an example of such modifications. Even though a small risk of infection transmission exists, it is outweighed by the benefit of rapid vaccination with limited personnel.

Single-use nozzle devices or disposable cartridge jet injectors (DCJIs) were developed to eliminate the risk factor associated with the use of MUNJIs [3, 8, 10]. In DCJIs, a disposable cartridge and nozzle are used, which prevent any splash back of blood onto the NFJI apparatus. Even though these devices were originally designed for low-workload conditions, devices that could administer injections at a rate of 600 shots per hour exist $[3,8]$. Recently, a huge shift in technological advancements has taken place, resulting in growing interest in administering needle-free injections. Newer designs that could be applied in multiple fields are being developed. This calls for the standardization of injectors and the U.S. Food and 
Drug Administration (USFDA) has issued some guidance in this regard $[11,12]$.

\section{Engineering aspects}

The purpose of an NFJI can be explained with the help of an analogy. It can be considered as a truck delivering a certain quantity of drug to a specified location inside the tissue layers, typically in intradermal, subcutaneous or intramuscular layers. Engineering principles are employed to energize the injecting fluid so that it can reach the targeted tissue layer and has an effective drug delivery.

\subsection{Design and types}

A conventional NFJI comprises a dose chamber with three major components: (a) An injection chamber having sufficient mechanical strength to hold the drug to be injected under pressure, (b) a nozzle with an orifice diameter of 50-360 $\mu \mathrm{m}$ $(\sim 150 \mu \mathrm{m})[1,13,14]$, and (c) a pressure source for energizing the injecting drug to form high-velocity microjets (typical velocity higher than $100 \mathrm{~m} / \mathrm{s}$ ). The pressure source may use direct action or the energy stored in a piston to energize the injecting fluid. A typical commercially available jet injector may use a piston to generate high-velocity microjets. The piston velocity is the key parameter that determines the penetration characteristics of the propelled microjet. The motion of the piston depends on various forces acting on it and can be expressed numerically as:

$$
m_{p} \ddot{x}_{p}=F_{D}(t)-F_{f}(t)-A_{p} p(t) .
$$

Here, $F_{D}(t)$ is the driving force generated by the energizing method, $F_{f}(t)$ is the frictional forced generated by the O-rings and other dissipative forces, $p(t)$ is the fluid resistance created by movement of piston in injection chamber, and $m_{p}$ and $A_{p}$ are the piston mass and surface area, respectively. The equation could be solved with the initial condition, at time $t=0$, the piston displacement $x_{p}=0$ and piston velocity $d x_{p} / d t=0$.

The force required for driving the piston could be generated by an expanding gas (usually $\mathrm{CO}_{2}$ or $\mathrm{N}_{2}$ ) or air [15-18], the energy from the sudden release of a compressed spring [1921], the Lorentz actuators [22-24] or piezoelectric actuators [25-27]. The Lorentz and piezoelectric actuators could provide electronic control over the injection speed. Recently, lasers [28-30] and shockwaves [31, 32] have been used to pressurize the injected fluid.

\subsubsection{Expanding gas/air}

Expanding gas or air is commonly used as the operating force in many commercially available NFJIs $[4,15,17]$ possibly because compressed gas can provide a higher energy density, improved flexibility and could deliver larger volumes of drugs. In these devices, an expanding gas accelerates the firing piston or ram, which in turn energizes the fluid to be injected by creating a high-pressure pulse. This high-pressure pulse causes a portion $(<10 \%)$ of the drug to be ejected at a high velocity (usually of the order of $200 \mathrm{~m} / \mathrm{s}$ ) and skin perforation usually occurs during this phase. Subsequently, the remaining phase of injection proceeds with a lower driving pressure to create jets with velocities of $100-150 \mathrm{~m} / \mathrm{s}$ that are dispersed through the penetration channel produced by the previous phase. The penetration depths of these devices could be controlled by varying the supply pressure and expanding volume. The compressed gas could be supplied by an air compressor or by gas generation via chemical means. In the latter case, a gas cartridge is attached to the device. The gas in the cartridge is released upon mechanical or electrical actuation. However, beside the compactness factor associated with these gas cartridges, they do have several disadvantages of complicated validation protocols, and foul odor due to the combustion reactants, which make them less appealing compared to an airpowered system. Engineering model of the system could be found in Refs. [15-17].

\subsubsection{Spring powered}

This is the one of the easiest and simplest methods for powering an NFJI. In this system, the energy stored during the mechanical compression of a spring is used to accelerate the driving piston. By adjusting the piston friction and the spring compression, the velocity range of the propelled microjet can be controlled (usually in the range $80-200 \mathrm{~m} / \mathrm{s}$ ). The driving force generated by a spring-powered NFJI is governed by Hooke's law. Baker et al. [19] provides a numerical model for designing a spring actuated NFJI system where Eq. (1) is modified as:

$$
m_{p} \ddot{x}_{p}=-k x_{p}-\dot{x}_{p} \frac{F_{f}(t)}{\left|\dot{x}_{p}\right|}-A_{p} p(t)
$$

where $k$ is the spring constant $(\mathrm{N} / \mathrm{m})$.

\subsubsection{Piezoelectric actuators}

Gas-powered and spring-powered NFJIs have a critical drawback. Once the initial parameters are set, users have little or no control over the injection parameters. Electrical control over the piston movement is effective for controlling the piston stroke and hence the injection parameters. Piezoelectric actuators are electronic actuators and with aid of mechanical amplification systems can provide dynamic control. In these systems, an electrically pulsed piezoelectric actuator is used to deliver injections. In contrast to other mechanisms, these devices electronically control the multilayer actuator expansion rate, thereby controlling the jet velocity and penetration characteristics. However, in a typical piezoelectric NFJI the injection volume may be in the nanoliter range (10 to $15 \mathrm{~nL})$ whereas most of the conventional NFJIs could inject volumes of 10 to $500 \mu \mathrm{L}$ [25-27]. Thus, repetitive or pulsed injections would be required to inject a large volume of the drug by a conventional piezoelectric NFJI. Stachowiak et al. [33] devel- 
oped a system where the piezoelectric vibrations could be mechanically amplified up to $900 \mu \mathrm{m}$ expansion and with much more control over the piston dynamics, thus controlling the velocity profile of the propelled microjet. The driving force obtained by the actuator expansion in Eq. (1) is:

$$
F_{D}(t)=C_{0} V(t)
$$

where $V(t)$ is the applied voltage and $C_{0}$ is the coefficient of proportionality given as $C_{0}=k_{a c t} X_{\max } / V_{\max }$, where $k_{\text {act }}$ is the actuator stiffness and $X_{\max }$ is the maximum expansion achieved by a voltage of $V_{\max }$.

\subsubsection{Lorentz force actuators}

Lorentz force actuators are electronic actuators as well, and they are more suitable for active control. A high-stroke linear Lorentz-force motor with feedback control can allow for realtime control of injection. The piston is connected to a Lorentzforce motor, which comprises a tightly wound copper coil and a magnetic circuit to produce the actuation force. The net driving force in Eq. (1) can be given as:

$$
F_{D}(t)=I \int d l \times B
$$

where $I$ is the current flow, $B$ is the magnetic field and $l$ is a vector whose magnitude is equal to the length of the wire and direction is along the direction of $I$. By regulating the current flow, one can control the force and thus the piston acceleration.

The MIT BioInstrumentation Laboratory [23] modified a spring-based NFJI into a Lorentz-force actuator that could generate an axial force of up to $\pm 200 \mathrm{~N}$ during the highpressure phase and demonstrated its repeatability in terms of independent control of injection depth and other parameters by controlling the high- and low-pressure phases. Refs. [22, 34-36] could give insight to the design of the electrical components and piston dynamics of the system.

\subsubsection{Direct actuated mechanisms}

One of the main factors limiting the applicability of current systems is jet diffusivity, which leads to the formation of a large dispersion pattern and unreliable penetration [29]. The diffusive jets may have increase in their jet diameter with the increase in stand-off distance and may affect the stagnation pressure on the skin surface $[17,24,37]$. The diffusive nature of the jets may be a reason to the pain and bruising associated with the current systems [26, 29]. Energizing the injected fluid using a piston and driving it through a micro-nozzle produces only diffusive jets. An alternative method to produce focused high-velocity microjets is using direct excitation with a laser or shockwaves in a capillary channel.

In a laser-induced microjet NFJI, a laser pulse is focused inside a capillary tube that is partially filled with the liquid to be injected. A vapor bubble is created and it emits a pressure wave through the fluid. The waves propagate toward the liq- uid interface and lead to the formation of a highly focused high-velocity microjet at the meniscus. Kinematic focusing owing to the curved interface of the meniscus aids in reducing jet dispersion. Highly focused microjets (diameter of approximately $30 \mu \mathrm{m}$ ) with velocities up to $850 \mathrm{~m} / \mathrm{s}$ could be achieved using a laser-activated system [27]. The pressure waves could be produced using alternate methods as well. There are reports on the use of diaphragms [29] and controlled explosions [30] to produce shockwaves for energizing the injected fluid directly [38].

Apart from the classification based on energy storage and source, NFJIs can be classified in many ways on the basis of the injected drug (liquid, powder, or projectile), delivery site (intradermal injectors, subcutaneous injectors and intramuscular injectors), reusability (MUNJIs and DCJIs), intended usage (e.g., self-administration or injection by a vaccinator), intended market (humans or veterinary), and way in which the injection chamber is filled (vial attached "on-tool" or filled "off-tool").

\subsection{Mechanism and factors}

Various in-vivo and in-vitro studies have been conducted to understand the mechanisms underlying an NFJI system [13, 39-41]. Based on the results of various studies, it is evident that the impinging high-velocity jet punctures the skin through erosion. The subsequent fracture mechanisms lead to the formation of a distinct hole [42]. Real-time or direct visualization of the propagation of microjets in skin layers is difficult owing to the non-homogeneous characteristics of the skin layers. Moreover, the elastic nature of the tissues tends to close the hole as soon as the injection is ceased. However, recent studies have made significant progress in identifying the penetration characteristics. Furthermore, drug delivery using an NFJI system can be considered as the effect of two events: Skin failure and convective flow though skin layers (viscoelastic porous media) [13]. The impinging high-velocity jet punctures the skin and penetrates until a critical depth, after which it disperses in a near-spherical pattern as depicted in Fig. 1. It has been reported that a stagnation pressure of $15 \mathrm{MPa}$ is adequate for the perforation of the human skin by a microjet with a diameter of 100-500 $\mu \mathrm{m}$ [43]. Although the operating principles of the devices vary, the peak pressure formed is usually in the range 14-35 MPa; it is formed during the initial phase of injection. Skin rupture and penetration may occur during this phase. Thereafter, the pressure drops to about one-third or two-third of the peak value and remains almost constant until a rapid tail-off at the end of the piston stroke. The drug is driven at a lower stream velocity during this phase so that the dispersion and absorption of the drug occurs in the surrounding tissues. The stagnation pressure acting on the skin surface due to an air-powered NFJ is shown in Fig. 2(a).

Visualization studies conducted using polyacrylamide (Fig. 2(b)) or gelatin mediums, materials that could mimic the Young's modulus of skin tissues, have confirmed these pro- 


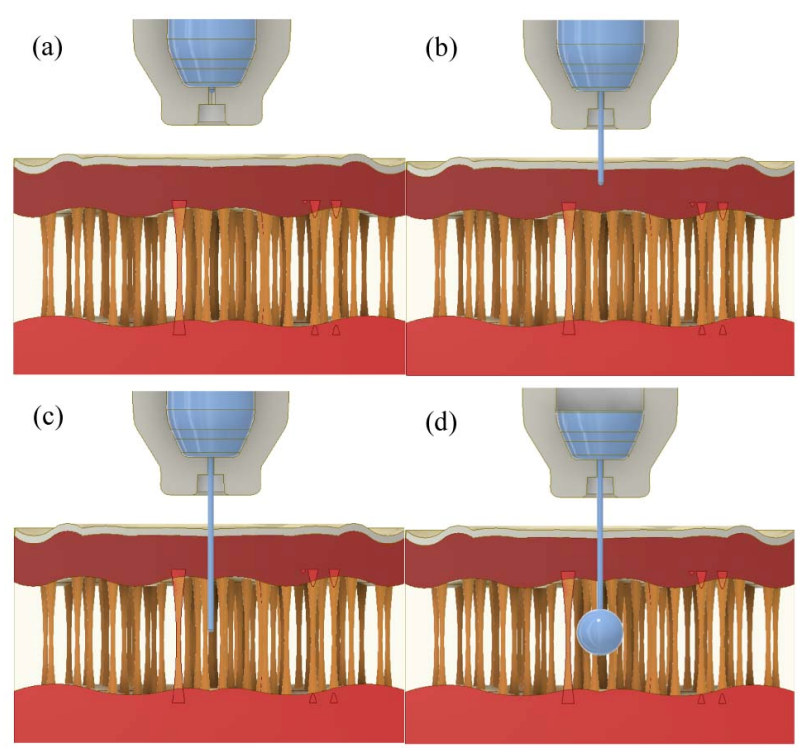

Fig. 1. Overall description of needle-free injection process: (a) Liquid inside the injection chamber is excited upon the impact of piston, leading to the formation of a microjet through the nozzle; (b) high-velocity microjet impacts skin surface and starts penetrating the surface when a certain threshold value of stagnation pressure is achieved (15 MPa for human skin); (c) penetration continues until it exhausts the energy to penetrate further into skin matrix. This phase may occur during the peak pressure regime in the initial phase of injection; (d) subsequent injection of the microjet causes spherical dispersion of the liquid inside skin layers.

files. However, the non-porous nature of these phantom medium leads to dispersion through the creation of penny-shaped cracks rather than the spherical dispersion profile observed in tissues [30, 40, 43]. Moreover, there exists a significant backflow of the jet during hole formation in the skin tissues, while there is no backflow in the holes created in polyacrylamide gels [42].

Furthermore, the penetration profile of an NFJI system varies based on the type of injection site (intradermal, subcutaneous and intramuscular) and the velocity or stagnation pressure characteristics of the microjet. Seok et al. performed a study to determine the depth and shape of an injected jet (Fig. 2(c)) [44]. They investigated the dependence of applied pressure on the penetration profile of an injected drug in a cadaver using an NFJI. They found that the depth and shape of dispersion was affected by the driving pressure when injected with materials of low density and viscosity. There was a great shift in the penetration characteristics based on the degree of applied pressure.

In general, the factors affecting the dispersion and penetration characteristics include the microjet velocity profile, chemical properties of the injected drug, and mechanical properties of the penetrated medium (Fig. 3). The microjet velocity profile depends on a number of factors, such as energizing power or driving force, volume of the drug to be injected, nozzle diameter, density and viscosity of the injected drug, injection chamber dimensions and stand-off distance [3,
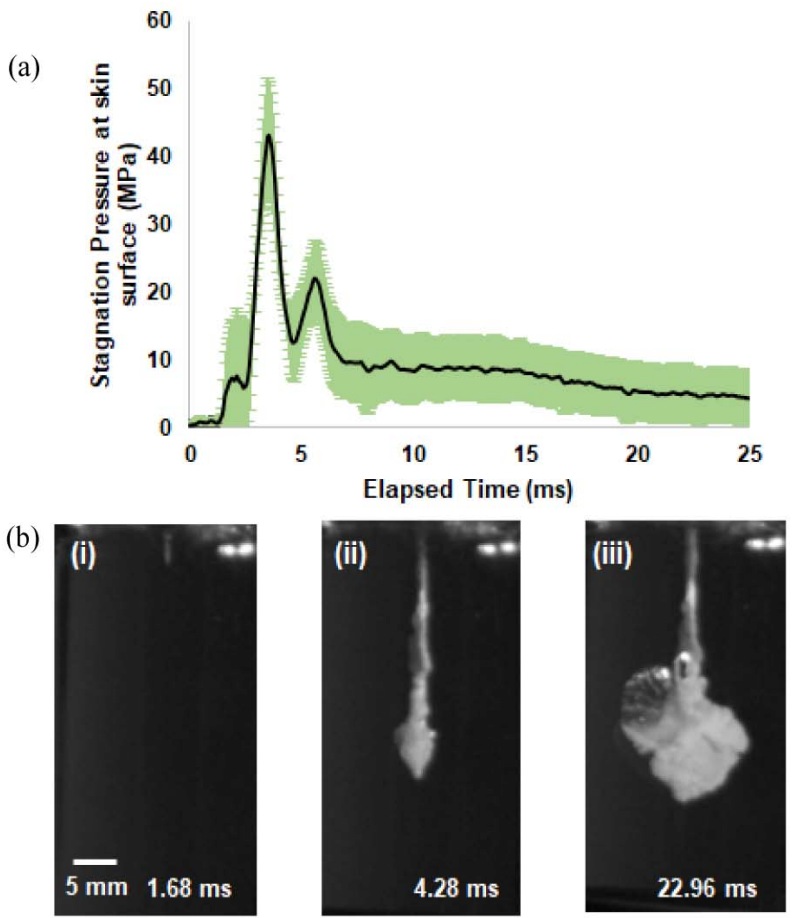

(c) (i)
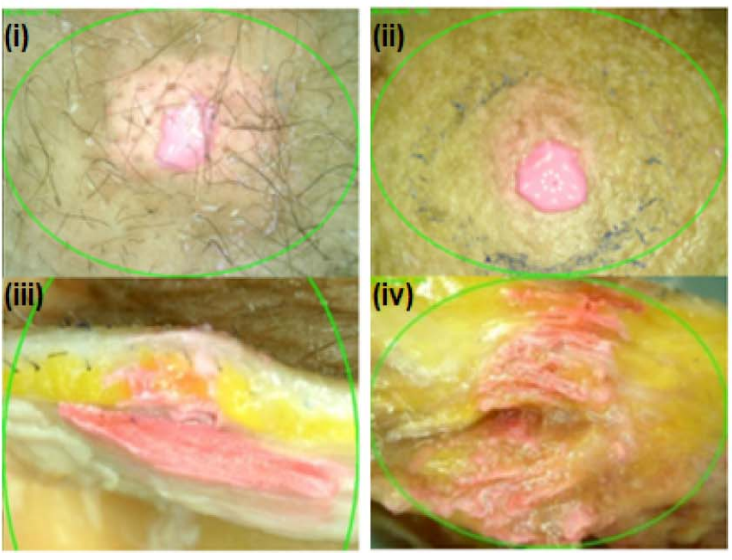

Fig. 2. Jet penetration characteristics: (a) Transient stagnation pressure data obtained for a commercial air-powered needle-free injector (Airjet $^{\mathrm{TM}}$, Union Medical, Uijeongbu-si, Gyeonggi-do, Korea). Stagnation pressure data were recorded at the exit of the protection cap of the device, i.e., at $5.9 \mathrm{~mm}$ from the nozzle exit. An experiment was performed under a driving pressure of $0.433 \mathrm{MPa}$ and a nozzle diameter of $200 \mu \mathrm{m}$ for an injection volume of $57.6 \mu \mathrm{L}$ (30\% filling volume of the injection chamber). The error band corresponds to the standard deviation obtained from a set of 7 experiments; (b) penetration characteristics of the microjet with the same parameters used for (a) in polyacrylamide medium. (i) The initiation of the penetration of the microjet into the medium. (ii) and (iii) The initial penetration depth and dispersion of the microjet, respectively, during the injection procedure; (c) Seok et al.'s observation of penetration characteristics of microjet in human tissue (human cadaver cheek) [44]. Penetration characteristics of latex administered by an air-powered NFJI (INNOJECTOR ${ }^{\mathrm{TM}}$, Amore Pacific, Seoul, Korea) were studied. (i) and (iii) The penetration characteristics of a microjet under a driving pressure of $0.6 \mathrm{MPa}$. Images show a semicircle-shaped hole that penetrated half the depth of the excised tissue. (ii) and (iv) Injection at driving pressure of $0.8 \mathrm{MPa}$ and a cylindrical profile that penetrated the entire depth of the tissue, respectively (adapted with permission from Fig. 4 in Ref. [44]). 


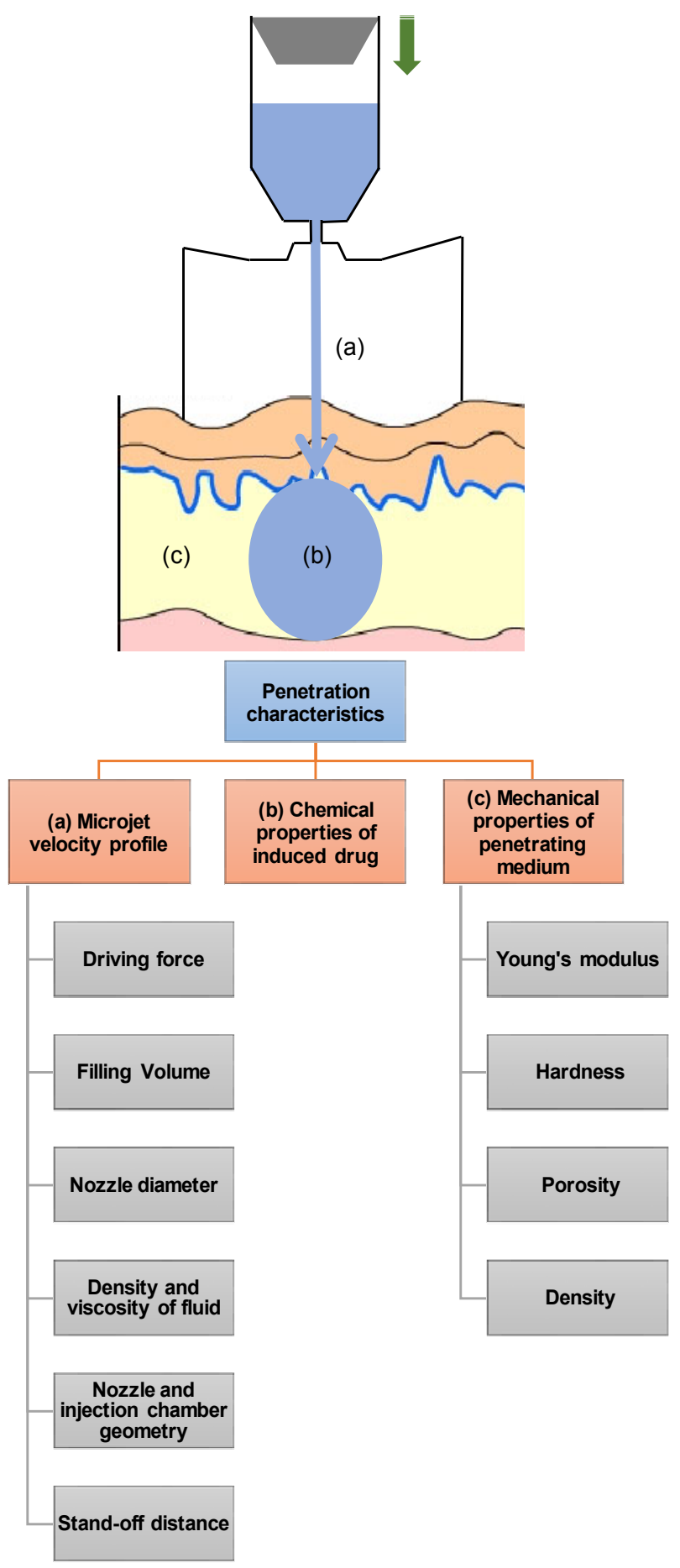

Fig. 3. Factors affecting microjet penetration characteristics.

$15,16,45-47]$. Stand-off distance can be defined as the distance from the nozzle exit to the skin surface, and it is a parameter that could be omitted from the performance evaluation of an NFJI. Ideally, the nozzle tip of the NFJI should be in contact with the skin surface. However, to avoid contamination, a safety cap was added as a safety measure. This created a clearance gap between the nozzle tip and the skin surface, which could affect the microjet velocity profile and penetra- tion characteristics owing to the variation in stand-off distance. The velocity characteristics can be quantitated as the velocity and jet diameter at skin surface. However, in pursuit of a single factor that could accommodate these factors, many researchers employ different approaches. Apart from the microjet velocity, jet power $[24,39]$ and stagnation pressure $[15,16]$ of the jet at the skin surface were reported as the quantifiers.

The jet power can be calculated as follows:

$$
P=\frac{1}{8} \pi \rho D^{2} U^{3}
$$

where $\rho$ is the fluid density, and $D$ and $U$ are the diameter and velocity of the microjet, respectively. The stagnation pressure on the skin surface can be expressed as follows:

$$
p \approx \frac{1}{2} \rho U^{2}
$$

The microjet velocity profile depends upon the type of NFJI used. Table 1 summarizes the parametric studies available in the literature. From the literatures, it is evident that the driving force, volume of fluid injected and nozzle diameter are the critical parameters on which the penetration characteristics of a particular injecting fluid depend. The parameters of the NFJI should be selected based on the target layer in the skin tissue, and an optimum nozzle design for various excitation methods is yet to be obtained. It is because the exact mechanism involved and the effect of various key parameters in various NFJI systems are still being explored, which points out the need of an extensive study on the effects of all the parameters in an NFJI system.

\section{Clinical applications}

The scope of the application of NFJIs is wide. This technology can be adapted to systems designed for needle-based injections, making it much more appealing in the modern era. Typically, an NFJI is an effective drug delivery method targeting intradermal, subcutaneous or intramuscular layers in skin and thus the same injector can be used for delivering more than one drug to the targeted layer in tissues. Many of the commercially available NFJIs are versatile [1], and the conventional applications are in vaccine and insulin delivery. Recently, they are being used in gene therapy and skin remodeling applications too. In skin remodeling applications, the function of the NFJI may not be limited to drug delivery. In these systems the propelled microjet may create a micro damage in tissue to activate growth factors. Thus the propelled microjets for this application may need higher velocity or stagnation pressure compared to other applications. Herein, we focus on the few important applications of NFJIs. Other applications are mentioned briefly. 
Table 1. Summary of the literature review on parametric studies of needle-free injectors.

\begin{tabular}{|c|c|c|c|c|}
\hline $\begin{array}{l}\text { Penetration } \\
\text { characteristics }\end{array}$ & Factor & NFJI type & Quantitative parameter & Effect \\
\hline \multirow{12}{*}{$\begin{array}{l}\text { Microjet velocity } \\
\text { profile }\end{array}$} & \multirow{4}{*}{ Driving force } & $\begin{array}{l}\text { Air or gas powered } \\
\text { (driving pressure) }\end{array}$ & $\begin{array}{l}\text { Stagnation pressure }[15-17] \text { and } \\
\text { penetration depth (gelatin [18], } \\
\text { cadaver [44]) }\end{array}$ & \multirow{4}{*}{ Increases with increase in driving force. } \\
\hline & & $\begin{array}{l}\text { Spring loaded } \\
\text { (preloading) }\end{array}$ & $\begin{array}{l}\text { Velocity of jet and stagnation } \\
\text { pressure [13], jet power [39] }\end{array}$ & \\
\hline & & $\begin{array}{c}\text { Piezoelectric } \\
\text { (supply voltage) }\end{array}$ & $\begin{array}{l}\text { Impact force and penetration } \\
\text { depth (polyacrylamide gel) [25] } \\
\text { and ex vivo porcine tissue [26]) }\end{array}$ & \\
\hline & & $\begin{array}{c}\text { Lorentz force } \\
\text { (supply voltage) }\end{array}$ & $\begin{array}{l}\text { Jet power [24], jet velocity [23] } \\
\text { and penetration depth (poly- } \\
\text { acrylamide gel }[22,23])\end{array}$ & \\
\hline & \multirow{3}{*}{$\begin{array}{l}\text { Nozzle } \\
\text { diameter }\end{array}$} & Air or gas powered & Stagnation pressure [15-17] & $\begin{array}{l}\text { No significant variation for nozzle diameter range of } 129 \text { - } \\
259 \mu \mathrm{m}[15,16] \text {. Peak stagnation pressure increased with } \\
\text { nozzle diameter (nozzle range: } 100-200 \mu \mathrm{m})[17] \text {. }\end{array}$ \\
\hline & & Spring loaded & $\begin{array}{l}\text { Percentage volume delivery (ex } \\
\text { vivo porcine tissue and human } \\
\text { skin) [13], impact pressure [21], } \\
\text { penetration depth (human skin } \\
{[39] \text { and polyacrylamide gel }} \\
[21,39])\end{array}$ & $\begin{array}{l}\text { Percentage volume delivery was maximum around } 152 \mu \mathrm{m} \\
\text { (nozzle range: } 76-559 \mu \mathrm{m} \text { ) [13]. Optimum diameter was } \\
\text { found to be } 300 \mu \mathrm{m} \text { (nozzle range: } 200-500 \mu \mathrm{m} \text { ) [21]. Depth } \\
\text { of fluid penetration increased with nozzle diameter (nozzle } \\
\text { range: } 31-559 \mu \mathrm{m} \text { ) [39]. }\end{array}$ \\
\hline & & Piezoelectric & $\begin{array}{l}\text { Stagnation pressure, jet velocity } \\
\text { and penetration depth (poly- } \\
\text { acrylamide gel) }[25]\end{array}$ & $\begin{array}{l}\text { Small rise in stagnation pressure and jet velocity with a } \\
\text { decrease in nozzle diameter (nozzle range: } 40-130 \mu \mathrm{m} \text { ). No } \\
\text { general trend for penetration depth. }\end{array}$ \\
\hline & \multirow{3}{*}{$\begin{array}{c}\text { Injection } \\
\text { volume and } \\
\text { fluid properties }\end{array}$} & Air or gas powered & $\begin{array}{l}\text { Stagnation pressure [17] and } \\
\text { penetration depth [18] }\end{array}$ & $\begin{array}{l}\text { Peak stagnation pressure increased with the decrease in } \\
\text { injecting volume for a piston stroke of } 7 \mathrm{~mm} \text { and stagnation } \\
\text { pressure values did not vary with selected fluids [17]. The } \\
\text { volume and density increased the penetration depth [18]. }\end{array}$ \\
\hline & & Spring loaded & $\begin{array}{l}\text { Jet force [20], jet velocity [20], } \\
\text { penetration depth and dispersion } \\
\text { radius (silicon rubber [47], poly- } \\
\text { acrylamide gel and ex vivo por- } \\
\text { cine tissue [20]) and efficacy of } \\
\text { tissue elevation (ex vivo porcine } \\
\text { tissue [39]) } \\
\end{array}$ & $\begin{array}{l}\text { Jet force and velocity directly increase with the volume } \\
\text { loaded, thereby increasing the penetration capabilities [20]. } \\
\text { Penetration depth decreased with an increase in injection } \\
\text { volume, while dispersion radius increased with an increase } \\
\text { in injection volume [47]. Independent of the viscosity of the } \\
\text { solution injected [39]. }\end{array}$ \\
\hline & & Piezoelectric & Jet velocity [25] & Jet velocity increases with decrease in filling volume. \\
\hline & & Air or gas powered & Stagnation pressure $[16,17]$ & Has negligible impact up to $25 \mathrm{~mm}$. \\
\hline & $\begin{array}{l}\text { Stand-off } \\
\text { distance }\end{array}$ & Spring loaded & $\begin{array}{l}\text { Penetration depth (human skin) } \\
{[39] \text {; delivery efficiency and }} \\
\text { dispersion area (human skin) } \\
{[41]}\end{array}$ & $\begin{array}{l}\text { Penetration depth decreases with an increase in stand-off } \\
\text { distance (variation is }<3 \mathrm{~mm} \text { for a stand-off distance up to } \\
6 \mathrm{~mm} \text { ) [39]. Delivery efficiency increased from } 60 \% \text { to } \\
\sim 90 \% \text { at a stand-off distance increase from } 1 \text { to } 3 \mathrm{~mm} \text {, while } \\
\text { dispersion area did not exhibit a significant change with the } \\
\text { stand-off distance [41]. }\end{array}$ \\
\hline $\begin{array}{l}\text { Mechanical } \\
\text { properties of } \\
\text { penetrating } \\
\text { medium }\end{array}$ & $\begin{array}{l}\text { Young's } \\
\text { modulus }\end{array}$ & Spring loaded & $\begin{array}{l}\text { Penetration depth (polyacryla- } \\
\text { mide gel) [40] }\end{array}$ & Decreased with increasing Young's modulus. \\
\hline
\end{tabular}

\subsection{Vaccine and Immunization}

Studies have shown that the intradermal vaccination could be better protection than other routes of immunization [48]. With a few exceptions, most forms of vaccinations are injected into intramuscular, subcutaneous, or intradermal space. Vaccine delivery to the targeted skin layer is a big challenge when employing needle injections. Needle-free vaccine deliv- ery is promoted by many public health organizations, including WHO, Centers for Disease Control and Prevention, and Global Alliance for Vaccines and Immunization, because of their numerous advantages including increased safety of vaccine, vaccinator and society; elimination of injection pain and needle phobia; easier and faster drug delivery; better amenability with vaccination schedules; and lower cost [49-54].

Several studies have shown that a vaccine delivered using 
an NFJI disperses more widely in tissues, typically with a spherical dispersion profile $[10,55,56]$. This wider dispersion could increase the contact volume between immune cells (such as lymphocytes) and vaccine antigens in tissues. This mechanism is believed to be responsible for enhanced responses after needle-free vaccinations of different antigens, such as typhoid, influenza, diphtheria-tetanus-pertussis, polio, meningitis, yellow fever, and hepatitis A vaccines [1, 10, 5557]. Injexk (Equidyne Systems, Tustin, CA, USA) and BiojectorR 2000 (Bioject Medical Technologies, Bedminster, NJ, USA) are examples of USFDA-approved injectors for vaccine delivery [58].

\subsection{Insulin}

Reluctance to use needles among diabetic patients has been a motivation for adopting NFJIs for insulin delivery. Denne et al.'s survey [59] conducted in 1992 showed that $84 \%$ of insulin users preferred NFJIs over a needle and syringe. Furthermore in 2001, Bremseth et al. [2] confirmed the acceptance of NFJIs (Medi-Jector Vision ${ }^{\mathrm{TM}}$, Antares Pharma, Ewing, NJ, USA) among people with diabetes. Better insulin dispersion could be achieved with an NFJI in comparison with that achieved with needle injection, and this could be the reason for the rapid increase in plasma injections applied using NFJIs $[60,61]$. However, there are reports of hematomas, bruising, bleeding, and immediate and delayed pain as adverse reactions to needle-free insulin delivery $[2,62]$.

\subsection{Skin rejuvenation}

Studies have shown that immediate dermal thickening could be achieved by injecting dermal fillers [63-65]. The effectiveness and longevity of these fillers depend on the volume of the drug injected [66, 67]. Moreover, injecting hyaluronic acid (HA) has been reported to trigger changes in fibroblast activity in the recipient's skin, resulting in increased collagen synthesis [68]. The injected drug can penetrate the dermis to a particular depth without affecting the surrounding tissues and induce dermal microtrauma that can stretch the fibroblasts, activating growth factors and constraining collagen breakdown. Airgent ${ }^{\mathrm{TM}}$ (PerfAction Ltd, Rehovot, Israel), a pneumatic NFJ, has been reported to have been used successfully for administering HA injections, and it could induce longlasting changes in the dermis. Therefore, it has been considered as an effective treatment for wrinkles [68]. Clinical studies have shown that injecting HA using Airgent ${ }^{\mathrm{TM}}$ is effective for treating atrophic acne scars as well [69]. Further research on administering HA in mice using INNOJECTOR ${ }^{\mathrm{TM}}$ (Amore Pacific, Seoul, Korea) showed that pneumatic injection of HA stabilizes collagen synthesis by targeting vimentin [70].

\subsection{Gene therapy}

DNA-based gene therapy has developed from an experi- mental technology into a viable strategy for the prevention and treatment of a wide range of human disorders. However, the lack of efficient delivery systems that could facilitate cellular internalization and preserve their activity was one of the barriers that hindered the wide use of this therapeutic mode [71-73]. More recently, NFJIs have been used for DNA-based therapies $[74,75]$ because it offers many advantages, such as circumvention of the exploitation of recombinant viral particles and zero or negligible toxicity and immunity problems. Another major advantage of NFJIs is that they can deliver DNA encapsulated in viral or non-viral vectors. Clinical studies on mice have shown that direct injection of low volumes (1.5$10 \mu \mathrm{l})$ of naked DNA could achieve tumor regression in mice [76]. In a phase I clinical trial by Walter et al., an NFJI of plasmid DNA was effective in patients with skin metastases due to melanoma or breast cancer [77]. In total, 0.05-mg hgalactosidase (LacZ)-expressing plasmid DNA (pCMVh) was injected five times into a single cutaneous lesion; no serious side effects were observed. In several clinical trials on the needle-free administration of HIV-1 antigens EnvA-, EnvB-, EnvC-, gagB-, polB- and nefB-encoding DNA vaccines (including HVTN204), followed by boosting with rAd5containing matching inserts, cellular and humoral immune responses were elicited [78, 79].

Kunugiza et al. [80] compared the effects of administering luciferase plasmid using a needle and an NFJI (Shima jet; Shimadzu Co. Ltd., Kyoto, Japan). Their results revealed that the local gene concentration was $\sim 100$ times higher with needle-free injection than with needle injection, and they concluded that needle-free administration was much more effective for wound healing. Nakagawa et al. [81] used a Shima jet to transfer the hepatocyte growth factor (HGF) and prostacyclin synthase (PGIS) genes for enhancing the survival of random-pattern skin flaps.

\subsection{Other applications}

NFJIs are widely used to administer growth hormones. The acceptance rate is considerably higher with NFJIs compared to that with needle injections because most patients are children. Comparative studies conducted by injecting human growth hormone (hGH) with needle and with NFJIs have indicated the bioequieffectiveness of needle-free hGH injections in both children and adults [82-85]. Injection of sedatives such as midazolam and anesthetics such as lidocaine using NFJIs have been reported [86-89]. In fact, they are commonly used in dermal surgical procedures, dental procedures and peripheral intravenous cannula insertion [3]. Syrijet Mark II (Keystone Industries, Cherry Hill, NJ, USA) is an example of an NFJI for anesthetics (1.8-mL cartridge) [90]. Moreover, there are reports on the use of NFJIs for injecting proteins, such as interferon [91] and erythropoietin [92], intravitreal delivery [93], low-molecular-weight heparin injections for deep vein thrombosis [94], and microsurgery [30, 95]. Advancements in engineering and medicine have widened the scope of the applica- 
tion of NFJIs.

\section{Conclusion and future prospects}

Even at a glance on the literatures, the impact of NFJIs on the world history as an effective tool in mass immunization campaigns is evident. Their ability to serve as high-workload devices with decreased risk of the transmission of infectious diseases and efficacy equivalent to needle injections earned them their mark. Even though these devices cost more than conventional needles and syringes, the savings achieved owing to increased speed and safety may advocate their use in mass campaigns. Currently, the applications of NFJIs are not restricted to vaccine or insulin delivery. Newer applications are sought out every day. The ease of modifying conventional needle-based systems into a needle-free system makes it more appealing in modern medicine. Although these systems have been under development for decades, their full potential has not been reached yet. Pain, edema, occasional bleeding and bruising and ecchymosis (occurring less often) are reported to occur more frequently with the use of NFJIs compared with those occurring with the use of needle injections $[1-3,69,85$, 96]. The occurrence of hematoma and transient neuropathy eye penetration when delivering an anesthetic during lower eyelid surgery have been reported in rare cases [1]. The exact reason for these reactions remains unknown.

Additional studies should be conducted to address numerous unanswered questions regarding microjet penetration, especially from the engineering viewpoint. Furthermore, research should be done to determine the exact penetration and dispersion mechanism, verify whether the injected drug remains intact, and investigate the impact of the mechanical properties of tissues (porosity, hardness, and toughness) on the dispersion characteristics. These topics can be considered as motivations for further research in this field.

\section{Acknowledgments}

This work was supported by grants from the Technology Innovation Program (10065332) of the Korea Evaluation Institute of Industrial Technology (KEIT) funded by the Ministry of Trade, Industry and Energy and also from the National Research Foundation (NRF) (NRF-2016R1D1A1A09917195) funded by the Ministry of Education, Republic of Korea. Abdul Mohizin was funded by the Global Scholarship Program for Foreign Graduate Students at Kookmin University in Seoul, Republic of Korea.

\section{References}

[1] B. G. Weniger and M. J. Papania, Alternative vaccine delivery methods, S. A. Plotkin, W. A. Orenstein and P. A. Offit (Eds.), Vaccines, Sixth Ed., Elsevier, Philadelphia, USA (2013) 1200-1231.

[2] D. L. Bremseth and F. Pass, Delivery of insulin by jet injection: recent observations, Diabetes Technol. Ther., 3 (2) (2001) 225-232.

[3] S. Mitragotri, Current status and future prospects of needlefree liquid jet injectors, Nat. Rev. Drug Discov., 5 (7) (2006) 543-548.

[4] B. G. Weniger, Needle-free jet injection bibliography, Device \& Manufacturer Roster, 2 (2000) 1998-2000.

[5] M. L. Lockhart, Hypodermic injector, US Patent 2322244A (1943).

[6] L. A. Jackson, G. Austin, R. T. Chen, R. Stout, F. DeStefano, G. J. Gorse, F. K. Newman, O. Yu and B. G. Weniger, Safety and immunogenicity of varying dosages of trivalent inactivated influenza vaccine administered by needle-free jet injectors, Vaccine, 19 (32) (2001) 4703-4709.

[7] B. G. Weniger, New high-speed jet injectors for mass vaccination: Pros and cons of disposable-cartridge jet injectors (DCJIs) versus multi-use-nozzle jet injectors (MUNJIS) (2004) http://apps.who.int/vaccine_research/ about/gvrf_2004/en/gvrf_2004_weniger.pdf.

[8] CDC, Morbidity and mortality weekly report (MMWR), General Recommendations on Immunization Recommendations of the Advisory Committee on Immunization Practices (ACIP) and the American Academy of Family Physicians (AAFP), 51 (RR-2) (2002) 1-35, http://www.cdc.gov/mmwr/ preview/mmwrhtml/rr5102a1.htm.

[9] J. Canter, K. Mackey, L. S. Good, R. R. Roberto, J. Chin, W. W. Bond, M. J. Alter and J. M. Horan, An outbreak of hepatitis B associated with jet injections in a weight reduction clinic, Arch. Intern. Med., 150 (9) (1990) 19231927.

[10] I. Parent du Chatelet, J. Lang, M. Schlumberger, E. Vidor, G. Soula, A. Genet, S. M. Standaert and P. Saliou, Clinical immunogenicity and tolerance studies of liquid vaccines delivered by jet-injector and a new single-use cartridge (Imule): comparison with standard syringe injection, Imule Investigators Group, Vaccine, 15 (4) (1997) 449-458.

[11] FDA, Technical considerations for pen, jet, and related injectors intended for use with drugs and biological products, (2013), http://www.fda.gov/downloads/regulatoryinformation/ guidances/ucm147095.pdf.

[12] FDA, FDA update communication on use of jet injectors with inactivated influenza vaccines (2014) http://www. fda.gov/BiologicsBloodVaccines/Vaccines/QuestionsaboutV accines/ucm276773.htm.

[13] J. Schramm and S. Mitragotri, Transdermal drug delivery by jet injectors: Energetics of jet formation and penetration, Pharm. Res., 19 (11) (2002) 1673-1679.

[14] O. A. Shergold, N. A. Fleck and T. S. King, The penetration of a soft solid by a liquid jet, with application to the administration of a needle-free injection, J. Biomech., 39 (14) (2006) 2593-2602.

[15] R. Portaro and H. D. Ng, Experiments and modeling of airpowered needle-free liquid injectors, J. Med. Biol. Eng., 35 (5) (2015) 685-695.

[16] H. Nakayama, R. Portaro, C. B. Kiyanda and H. D. Ng, Cfd 
modeling of high speed liquid jets from an air-powered needle-free injection system, J. Mech. Med. Biol., 16 (04) (2016) 1650045.

[17] A. Mohizin, K. E. R. Roy, D. Lee, S. K. Lee and J. K. Kim, Computational fluid dynamics of impinging microjet for a needle-free skin scar treatment system, Comput. Biol. Med., 101 (2018) 61-69.

[18] T. M. Grant, K. D. Stockwell, J. B. Morrison and D. D. Mann, Effect of pressure, volume and density on the jet dispersion of needle-free injection devices, Biosyst. Eng., 8 (2015) 4-9.

[19] A. B. Baker and J. E. Sanders, Fluid mechanics analysis of a spring-loaded jet injector, IEEE Trans. Biomed. Eng., 46 (2) (1999) 235-242.

[20] A. Schoubben, A. Cavicchi, L. Barberini, A. Faraon, M. Berti, M. Ricci, P. Blasi and L. Postrioti, Dynamic behavior of a spring-powered micronozzle needle-free injector, Int. J. Pharm., 491 (1-2) (2015) 91-98.

[21] D. Zeng, Y. Kang, L. Xie, X. Xia, Z. Wang and W. Liu, A mathematical model and experimental verification of optimal nozzle diameter in needle-free injection, J. Pharm. Sci., 107 (4) (2018) 1086-1094.

[22] R. M. J. Williams, N. C. Hogan, P. M. F. Nielsen, I. W. Hunter and A. J. Taberner, A computational model of a controllable needle-free jet injector, Proc. Annu. Int. Conf. IEEE Eng. Med. Biol. Soc. EMBS (2012) 2052-2055.

[23] A. Taberner, N. C. Hogan and I. W. Hunter, Needle-free jet injection using real-time controlled linear Lorentz-force actuators, Med. Eng. Phys., 34 (9) (2012) 1228-1235.

[24] G. Park, A. Modak, N. C. Hogan and I. W. Hunter, The effect of jet shape on jet injection, Proc. Annu. Int. Conf. IEEE Eng. Med. Biol. Soc. EMBS (2015) 7350-7353.

[25] J. C. Stachowiak, M. G. von Muhlen, T. H. Li, L. Jalilian, S. H. Parekh and D. A. Fletcher, Piezoelectric control of needle-free transdermal drug delivery, J. Control. Release, 124 (1-2) (2007) 88-97.

[26] A. Arora, I. Hakim, J. Baxter, R. Rathnasingham, R. Srinivasan, D. A. Fletcher and S. Mitragotri, Needle-free delivery of macromolecules across the skin by nanolitervolume pulsed microjets, Proc. Natl. Acad. Sci., 104 (11) (2007) 4255-4260.

[27] A. M. Römgens, D. Rem-Bronneberg, R. Kassies, M. Hijlkema, D. L. Bader, C. W. J. Oomens and M. P. B. Van Bruggen, Penetration and delivery characteristics of repetitive microjet injection into the skin, $J$. Control. Release, 234 (2016) 98-103.

[28] I. R. Peters, Y. Tagawa, N. Oudalov, C. Sun, A. Prosperetti, D. Lohse and D. van der Meer, Highly focused supersonic microjets: numerical simulations, J. Fluid Mech., 719 (2013) 587-605.

[29] Y. Tagawa, N. Oudalov, A. El Ghalbzouri, C. Sun and D. Lohse, Needle-free injection into skin and soft matter with highly focused microjets, Lab Chip, 13 (7) (2013) 1357-63.

[30] T. Kato, T. Arafune, T. Washio, A. Nakagawa, Y. Ogawa, T. Tominaga, I. Sakuma and E. Kobayashi, Mechanics of the injected pulsejet into gelatin gel and evaluation of the effect by puncture and crack generation and growth, J. Appl. Phys., 116 (7) (2014) 074901.

[31] M. A. F. Kendall, The delivery of particulate vaccines and drugs to human skin with a practical, hand-held shock tubebased system, Shock Waves, 12 (1) (2002) 23-30.

[32] G. Jagadeesh, G. D. Prakash, S. G. Rakesh, U. S. Allam, M. G. Krishna, S. M. Eswarappa and D. Chakravortty, Microshock waves mediated needle-less vaccine delivery, Clin. Vaccine Immunol., 18 (4) (2011) 539-545.

[33] J. C. Stachowiak, T. H. Li, A. Arora, S. Mitragotri and D. A. Fletcher, Dynamic control of needle-free jet injection, $J$. Control. Release, 135 (2) (2009) 104-112.

[34] B. P. Ruddy, A. W. Dixon, R. M. J. Williams and A. J. Taberner, Optimization of portable electronically controlled needle-free jet injection systems, IEEE/ASME Trans. Mechatronics, 22 (5) (2017) 2013-2021.

[35] J. W. McKeage, B. P. Ruddy, P. M. F. Nielsen and A. J. Taberner, A device for controlled jet injection of large volumes of liquid, Proc. Annu. Int. Conf. IEEE Eng. Med. Biol. Soc. EMBS (2016) 553-556.

[36] B. D. Hemond, D. M. Wendell, N. C. Hogan, A. J. Taberner and I. W. Hunter, A Lorentz-force actuated autoloading needle-free injector, Proc. Annu. Int. Conf. IEEE Eng. Med. Biol. Soc. EMBS (2006) 679-682.

[37] J. K. Kim, A. Mohizin and S. K. Lee, Experimental investigation on key parameters in air-powered needle-free injection system for skin treatment, J. Korean Soc. Vis., 16 (1) (2018) 42-47.

[38] G. Zhang, Y. Z. Jin, T. Setoguchi and H. D. Kim, Study on drug powder acceleration in a micro shock tube, J. Mech. Sci. Technol., 30 (9) (2016) 4007-4013.

[39] J. Schramm-Baxter and S. Mitragotri, Needle-free jet injections: Dependence of jet penetration and dispersion in the skin on jet power, J. Control. Release, 97 (3) (2004) 527535.

[40] J. Schramm-Baxter, J. Katrencik and S. Mitragotri, Jet injection into polyacrylamide gels: investigation of jet injection mechanics, J. Biomech., 37 (8) (2004) 1181-1188.

[41] Y. Michinaka and S. Mitragotri, Delivery of polymeric particles into skin using needle-free liquid jet injectors, $J$. Control. Release, 153 (3) (2011) 249-254.

[42] J. Baxter and S. Mitragotri, Jet-induced skin puncture and its impact on needle-free jet injections: Experimental studies and a predictive model, J. Control. Release, 106 (3) (2005) 361-373.

[43] O. A. Shergold and N. A. Fleck, Mechanisms of deep penetration of soft solids, with application to the injection and wounding of skin, Proc. R. Soc. A Math. Phys. Eng. Sci., 460 (2050) (2004) 3037-3058.

[44] J. Seok, C. T. Oh, H. J. Kwon, T. R. Kwon, E. J. Choi, S. Y. Choi, S. K. Mun, S. H. Han, B. J. Kim and M. N. Kim, Investigating skin penetration depth and shape following needle-free injection at different pressures: A cadaveric study, Lasers Surg. Med., 48 (6) (2016) 624-628. 
[45] A. Repici, R. Maselli, S. Carrara, A. Anderloni, M. Enderle and C. Hassan, Standard needle versus needleless injection modality: animal study on different fluids for submucosal elevation, Gastrointest. Endosc., 86 (3) (2017) 553-558.

[46] N. Rajaratnam, S. A. H. Rizvi, P. M. Steffler and P. R. Smy, An experimental study of very high velocity circular water jets in air, J. Hydraul. Res., 32 (3) (1994) 461-470.

[47] K. Chen, H. Zhou, J. Li and G. J. Cheng, A model on liquid penetration into soft material with application to needle-free jet injection, J. Biomech. Eng., 132 (10) (2010) 101005.

[48] B. D. Hunsaker and L. J. Perino, Efficacy of intradermal vaccination, Vet. Immunol. Immunopathol., 79 (1-2) (2001) $1-13$.

[49] R. M. Jacobson, A. Swan, A. Adegbenro, S. L. Ludington, P. C. Wollan and G. A. Poland, Making vaccines more acceptable - methods to prevent and minimize pain and other common adverse events associated with vaccines, Vaccine, 19 (17-19) (2001) 2418-2427.

[50] D. U. Ekwueme, B. G. Weniger and R. T. Chen, Modelbased estimates of risks of disease transmission and economic costs of seven injection devices in sub-Saharan Africa, Bull. World Health Organ., 80 (11) (2002) 859-870.

[51] E. H. Moylett and I. C. Hanson, Mechanistic actions of the risks and adverse events associated with vaccine administration, J. Allergy Clin. Immunol., 114 (5) (2004) 1010-1020.

[52] M. M. Levine and M. B. Sztein, Vaccine development strategies for improving immunization: The role of modern immunology, Nat. Immunol., 5 (5) (2004) 460-464.

[53] M. Dicko, A. Q. Oni, S. Ganivet, S. Kone, L. Pierre and B. Jacquet, Safety of immunization injections in Africa: not simply a problem of logistics, Bull. World Health Organ., 78 (2) (2000) 163-169.

[54] L. Simonsen, A. Kane, J. Lloyd, M. Zaffran and M. Kane, Unsafe injections in the developing world and transmission of bloodborne pathogens: A review, Bull. World Health Organ., 77 (10) (1999) 789-800.

[55] A. Fisch, P. Cadilhac, E. Vidor, T. Prazuck, A. Dublanchet and C. Lafaix, Immunogenicity and safety of a new inactivated hepatitis A vaccine: A clinical trial with comparison of administration route, Vaccine, 14 (12) (1996) 1132-1136.

[56] J. Williams, L. Fox-Leyva, C. Christensen, D. Fisher, E. Schlicting, M. Snowball, S. Negus, J. Mayers, R. Koller and R. Stout, Hepatitis A vaccine administration: Comparison between jet-injector and needle injection, Vaccine, 18 (18) (2000) 1939-1943.

[57] S. Mitragotri, Immunization without needles, Nat. Rev. Immunol., 5 (12) (2005) 905-916.

[58] E. L. Giudice and J. D. Campbell, Needle-free vaccine delivery, Adv. Drug Deliv. Rev., 58 (1) (2006) 68-89.

[59] J. R. Denne, K. L. Andrews, D. V Lees and W. Mook, A survey of patient preference for insulin jet injectors versus needle and syringe, Diabetes Educ., 18 (3) (1992) 223-227.

[60] C. Weller and M. Linder, Jet injection of insulin vs the syringe-and-needle method, JAMA, 195 (10) (1966) 844-847. [61] G. B. Pehling and J. E. Gerich, Comparison of plasma insulin profiles after subcutaneous administration of insulin by jet spray and conventional needle injection in patients with insulin-dependent diabetes mellitus, Mayo Clin. Proc., 59 (11) (1984) 751-754.

[62] C. M. G. J. Houtzagers, A. Ph. Visser, P. A. Berntzen, R. J. Heine and E. A. van der Veen, The Medi - Jector II: Efficacy and acceptability in insulin - dependent diabetic patients with and without needle phobia, Diabet. Med., 5 (1988) 135-138.

[63] M. H. Gold, What's new in fillers in 2010, J. Clin. Aesthetic Dermatology, 3 (8) (2010) 36-45.

[64] M. H. Gold, Use of hyaluronic acid fillers for the treatment of the aging face, Clin. Interv. Aging, 2 (3) (2007) 369-376.

[65] T. Kono, B. M. Kinney, W. F. Groff, H. H. Chan, A. R. Ercocen and M. Nozaki, Randomized, evaluator-blind, splitface comparison study of single cross-linked versus double cross-linked hyaluronic acid in the treatment of glabellar lines, Dermatologic Surg., 34 (SUPPL 1) (2008) 25-30.

[66] P. E. Kelly, Injectable success: From fillers to Botox, Facial Plast. Surg., 23 (1) (2007) 7-18.

[67] M. P. Lupo, Hyaluronic acid fillers in facial rejuvenation, Semin. Cutan. Med. Surg., 25 (3) (2006) 122-126.

[68] A. Levenberg, S. Halachmi, A. Arad-Cohen, D. Ad-El, D. Cassuto and M. Lapidoth, Clinical results of skin remodeling using a novel pneumatic technology, Int. J. Dermatol., 49 (12) (2010) 1432-1439.

[69] J. W. Lee, B. J. Kim, M. N. Kim and C. K. Lee, Treatment of Acne scars using subdermal minimal surgery technology, Dermatologic Surg., 36 (8) (2010) 1281-1287.

[70] T. R. Kwon, J. Seok, J. H. Jang, M. K. Kwon, C. T. Oh, E. J. Choi, H. K. Hong, Y. S. Choi, J. Bae and B. J. Kim, Needle-free jet injection of hyaluronic acid improves skin remodeling in a mouse model, Eur. J. Pharm. Biopharm., 105 (2016) 69-74.

[71] S. D. Patil, D. G. Rhodes and D. J. Burgess, DNA-based therapeutics and DNA delivery systems: A comprehensive review, AAPS J., 7 (1) (2005) E61-E77.

[72] E. Check, Shining hopes dented - but not dashed, Nature, 420 (6917) (2002) 735.

[73] E. Marshall, Gene therapy death prompts review of adenovirus vector, Science, 286 (5448) (1999) 2244-2245.

[74] P. A. Furth, A. Shamay and L. Hennighausen, Gene transfer into mammalian cells by jet injection, Hybridoma, 14 (2) (1995) 149-152.

[75] Y. Taniyama, J. Azuma, Y. Kunugiza, K. Iekushi, H. Rakugi and R. Morishita, Therapeutic option of plasmidDNA based gene transfer, Curr. Top. Med. Chem., 12 (15) (2012) 1630-1637.

[76] W. Walther, U. Stein, I. Fichtner, C. Voss, T. Schmidt, M. Schleef, T. Nellessen and P. M. Schlag, Intratumoral lowvolume jet-injection for efficient nonviral gene transfer, Mol. Biotechnol., 21 (2) (2002) 105-115.

[77] W. Walther, R. Siegel, D. Kobelt, T. Knösel, M. Dietel, A. 
Bembenek, J. Aumann, M. Schleef, R. Baier, U. Stein and P. M. Schlag, Novel jet-injection technology for nonviral intratumoral gene transfer in patients with melanoma and breast cancer, Clin. Cancer Res., 14 (22) (2008) 7545-7553.

[78] C. G. Beckett, J. Tjaden, T. Burgess, J. R. Danko, C. Tamminga, M. Simmons, S.-J. Wu, P. Sun, T. Kochel, K. Raviprakash, C. G. Hayes and K. R. Porter, Evaluation of a prototype dengue-1 DNA vaccine in a Phase 1 clinical trial, Vaccine, 29 (5) (2011) 960-968.

[79] M. Raska and J. Turanek, DNA vaccines for the induction of immune responses in mucosal tissues, Fourth Ed., Elsevier (2015).

[80] Y. Kunugiza, N. Tomita, Y. Taniyama, T. Tomita, M. K. Osako, K. Tamai, T. Tanabe, Y. Kaneda, H. Yoshikawa and R. Morishita, Acceleration of wound healing by combined gene transfer of hepatocyte growth factor and prostacyclin synthase with Shima Jet, Gene Ther., 13 (15) (2006) 1143-1152.

[81] A. Nakagawa, H. Makino, M. Aoki, T. Miyake, S. Shiraya, T. Nakamura, T. Ogihara, Y. Kimata and R. Morishita, Improvement of survival of skin flaps by combined gene transfer of hepatocyte growth factor and prostacyclin synthase, J. Gene Med., 9 (2007) 1087-1094.

[82] A. M. Pereira, A. A. van der Klaauw, H. P. F. Koppeschaar, J. W. A. Smit, S. W. van Thiel, J. van Doorn, N. R. Biermasz, F. Roelfsema and J. A. Romijn, Efficacy of needle-free administration of recombinant human growth hormone in adults with growth hormone deficiency, $B r . J$. Clin. Pharmacol., 61 (4) (2006) 451-455.

[83] H. Agersø, J. Møller-Pedersen, S. Cappi, P. Thomann, B. J. Jesussek and T. Senderovitz, Pharmacokinetics and pharmacodynamics of a new formulation of recombinant human growth hormone administered by zomajet 2 vision, a new needle-free device, compared to subcutaneous administration using a conventional syringe, J. Clin. Pharmacol., 42 (12) (2002) 1262-1268.

[84] A. Verhagen, J. T. Ebels, A. A. Dogterom and J. H. Jonkman, Pharmacokinetics and pharmacodynamics of a single dose of recombinant human growth hormone after subcutaneous administration by jet-injection: comparison with conventional needle-injection, Eur. J. Clin. Pharmacol., 49 (1-2) (1995) 69-72.

[85] P. Bareille, M. MacSwiney, A. Albanese, C. De Vile and R. Stanhope, Growth hormone treatment without a needle using the Preci-Jet 50 transjector, Arch. Dis. Child., 76 (1) (1997) 65-67.

[86] N. Jimenez, H. Bradford, K. D. Seidel, M. Sousa and A. M. Lynn, A comparison of a needle-free injection system for local anesthesia versus EMLA for intravenous catheter insertion in the pediatric patient, Anesth. Analg., 102 (2) (2006) 411-414.

[87] A. K. Munshi, A. Hegde and N. Bashir, Clinical evaluation of the efficacy of anesthesia and patient preference using the needle-less jet syringe in pediatric dental practice, J. Clin. Pediatr. Dent., 25 (2) (2001) 131-136.

[88] E. K. Zsigmond, P. Darby, H. M. Koenig and E. F. Goll, Painless intravenous catheterization by intradermal jet injection of lidocaine: A randomized trial, J. Clin. Anesth., 11 (2) (1999) 87-94.

[89] R. S. Greenberg, L. G. Maxwell, M. Zahurak and M. Yaster, Preanesthetic medication of children with midazolam using the Biojector jet injector, Anesthesiology, 83 (2) (1995) 264-269.

[90] J. E. Jones and J. A. Dean, Chapter 15 - Local anesthesia and pain control for the child and adolescent, McDonald Avery's Dentistry for the Child and Adolescent, Tenth Ed., Mosby, St. Louis, USA (2016) 274-285.

[91] R. T. Brodell and D. L. Bredle, The treatment of palmar and plantar warts using natural alpha interferon and a needleless injector, Dermatol. Surg., 21 (3) (1995) 213-218.

[92] T. Suzuki, I. Takahashi and G. Takada, Daily subcutaneous erythropoietin by jet injection in pediatric dialysis patients, Nephron, 69 (3) (1995) 347.

[93] H. Ren, B. S. Yeow, J. Sun and J. V. Iyer, Electromagnetic needleless injector with halbach array towards intravitreal delivery, IEEE Access, 6 (2017) 1267-1276.

[94] S. J. Hollingsworth, K. Hoque, D. Linnard, D. G. Corry and S. G. Barker, Delivery of low molecular weight heparin for prophylaxis against deep vein thrombosis using a novel, needle-less injection device (J-Tip), Ann. R. Coll. Surg. Engl., 82 (6) (2000) 428-431.

[95] D. A. Fletcher and D. V. Palanker, Pulsed liquid microjet for microsurgery, Appl. Phys. Lett., 78 (13) (2001) 1933-1935.

[96] U. Schneider, R. Birnbacher and E. Schober, Painfulness of needle and jet injection in children with diabetes mellitus, Eur. J. Pediatr., 153 (6) (1994) 409-410.

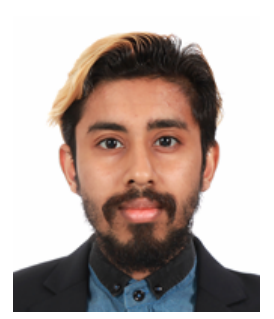

Abdul Mohizin received his B.Tech. and M.Tech. degrees in Mechanical Engineering from Kerala University, Kerala, India, in 2013 and 2016, respectively. He joined the Biomedical Device Lab in 2017 as a doctoral student at Kookmin University, Seoul, South Korea. His current research interests include computational fluid dynamics, two phase flows, tissue fluid interactions, needle-free injection systems and biomedical devices.

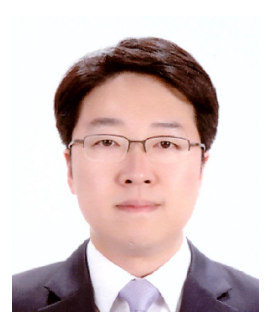

Jung Kyung Kim received his B.S. degree in Mechanical Engineering in 1996 and then his M.S. and Ph.D. degrees both in Biomedical Engineering at Seoul National University in 1998 and 2003, respectively. From July 2004 to August 2006, he was a postdoctoral fellow in the Departments of Medicine and Physiology, University of California, San Francisco, USA. After joining Kookmin University based in Seoul, South Korea in September 2006 as an Assistant Professor, he has been directing Biomedical Device Lab and currently serves as a Tenured Professor in School of Mechanical Engineering. 